\title{
The Digital Design of Imitation Antique Building
}

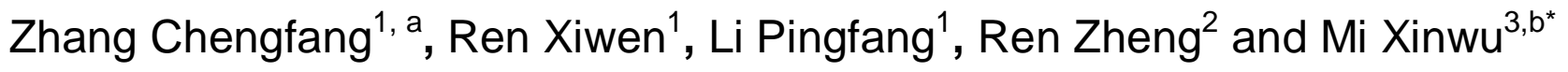 \\ ${ }^{1}$ School of civil engineering, Wuhan Huaxia University of Technology, P.R.China \\ ${ }^{2}$ Hubei Industrial Polytechnic, P.R.China \\ ${ }^{3}$ School of urban design, Wuhan University, P.R.China \\ a5652453@qq.com, b2690909501@qq.com
}

Keywords: Digital design; Yushan Hall; Polygon modeling; Regional culture

Abstract. Digital design is a kind of emerging forms of expression in the digital era, and plays an essential role in architectural design. During the process of digital design technology application, when designer pursues the technology for digital performs, sometimes, they probably only focus on drawing effect and then disadvantages will appear that works lack designed analyses and artistic connotations. In the design of Yunshan Hall, we strive to abandon those disadvantages. We optimize technology platform for digital design and pay attention to humanized design and the application of geographical context factors. Yunshan Hall shape will be designed to have the characteristics of Northwest Hubei residential high-class club-style hotel by the survey and analysis for residential buildings in Yunyang area.

\section{Introduction}

With the development of computer and internet technology, technology of digital aided design breaks the traditional designed techniques that it uses the means of new digital technology to display the designed modelling, material, color, material, and other information in the digital form [1]. The working mode of changing design affects the way of thinking and the idea of design of the designer, and at the same time, it will change the form and connotation of space design that provides architects with greater space of development to exert their creative ability, imagination and expressive ability.

\section{Design idea for Yunshan Hall}

Design Requirements. Shiyan area formerly known as Yunyang which locates in Hubei province, and adjacent to Henan, Chongqing, and Shanxi, is situated in the hinterland of Qinling Mountains, south of the Han River, with abundant geographical and cultural characteristics [2]. "Yunshan Hall" design requires that breaking through this geographical features, emphasizing the sense of closure and the center of area. Meanwhile, it also requires harmony with the terrain and the environment, the use of the traditional patio, corridor, the construction of the district both self-contained and complement each other; What's more, "Yunshan Hall" also pay attention to the sight of sightseeing, the building height strictly controlled within $10 \mathrm{~m}$, and with the terrain designed into a high and low scattered, vivid and exciting architectural forms to ensure that each space does not interfere with each other and combine with the actual terrain for vertical design. With Studying the horizontal layout of local dwelling practice, respecting the location of the contour line, the original ecological environment is not changed basically and the architecture is integrated into the original 
environment. The design of artificial landscapes is as far as possible with water. The main sections are planted with bamboo or trees which are used to keep out, and planted a wide range of turf.

The standard room of the second floor equipped terrace that the area of construction is about 40 square meters. The appearance absorbs the essence of the private house in the northwest of Hubei that try to use local materials such as stone, bamboo, wood and so on. Color collocation requires tradition and permanence and does not pursue popular elements, so that the color of the exterior wall can be dissolved into the landscape. While focusing on privacy, place the bathtub where you can view the scenery. A Chinese courtyard surrounded by a few luxurious rooms and equipped with the outdoor pavilion, the pool and the garden. With making full use of cheap local materials, we use the excellent design and exquisite artistry to create luxurious and comfortable rooms.

Design idea. The design of "Yunshan Hall" reflect fully the geographical features of Yunyang and inherit the tenet of Chu Culture [3]. The deep research on Yunyang private house (Fig. 1) ensures that the design is based on the recreation of local characteristics. "Yunshan Hall" will be extensive use of the traditional street gates, Hanging edge of a dripping tile, Arc-shaped arch, Small ash tile, Hard mountain, a screen wall facing the entrance of a house and other architectural elements of the Yunyang old private house and it will focus on the reconstruction of the art of structure that includes the garden, courtyard and field of the Yunyang old private house [4-6]. Houses adopt gables and warped roofs and combine the aesthetic habits of Yunyang people and the modern way of life in the aeration, orientations, light selecting and other aspects. In order to make the landscape and the greening have the amorous feeling by trying our best, blue slates are used to pave pavements between the hall building and the cobblestones or corresponding stones are used to pave lane. In the main style and subtlety, it displays the thick and heavy sense of Yunyang buildings and builds the view of a small bridge over the flowing stream, beautiful planting, special features, natural local customs.

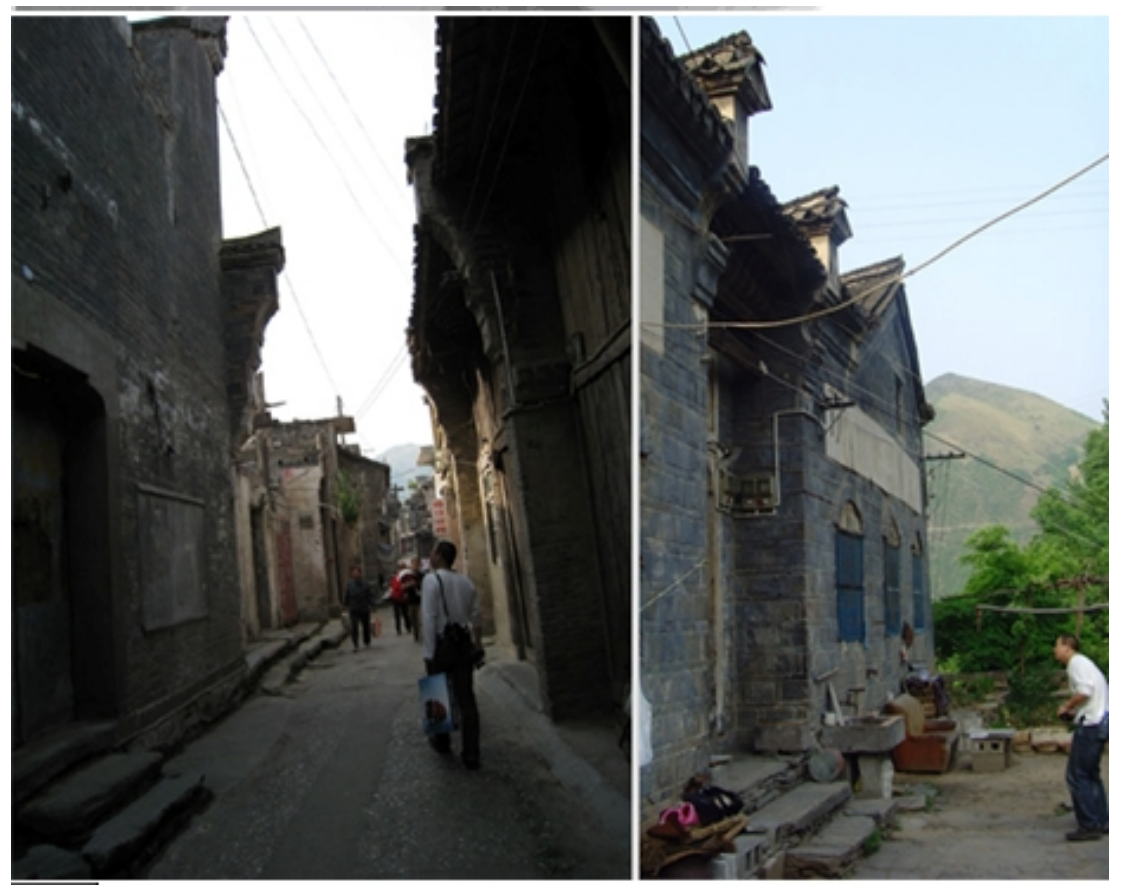

Figure 1. Ancient houses at Baihe county in old county.

\section{Project design}

Modeling method. The general idea of the design of Yunyang Hall is to transplant the essence of Bachu style, scholarly people and the ancient Shang State to create the necessary geometry on the 
basis of the survey of Yunyang dwelling houses, to create the virtual reality works through lofting, modeling, and combination, According to the requirements of the virtual reality system, the model parameters are adjusted to obtain the models with different resolutions to meet the needs of real-time display of virtual scenes. It is proposed to build "Yunyang Hall" into an authentic Yunyang Cultural House.
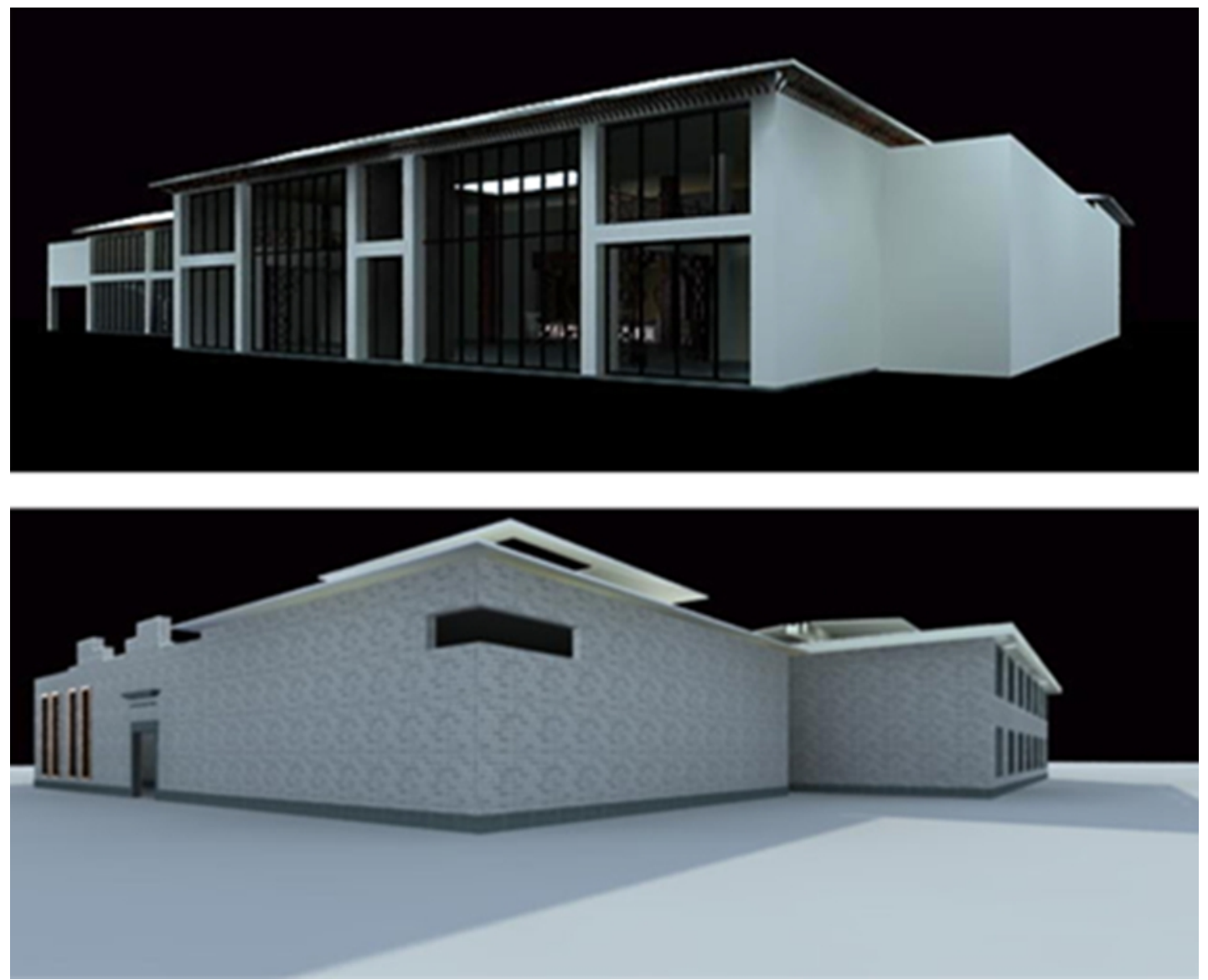

Figure 2. Style is artistic, bright and modern.

In line with the purpose that reflect local features of Yunyang and inherit Chu culture, we designed two different styles of the basic body of Yunyang Hall. The first style is designed to be artistic and lively, with a strong sense of modernity (Fig. 2). The second style is simple and heavy that can be closer to the Yunyang private house, and it is also easier to integrate into the mountains and wilderness (Fig. 3).

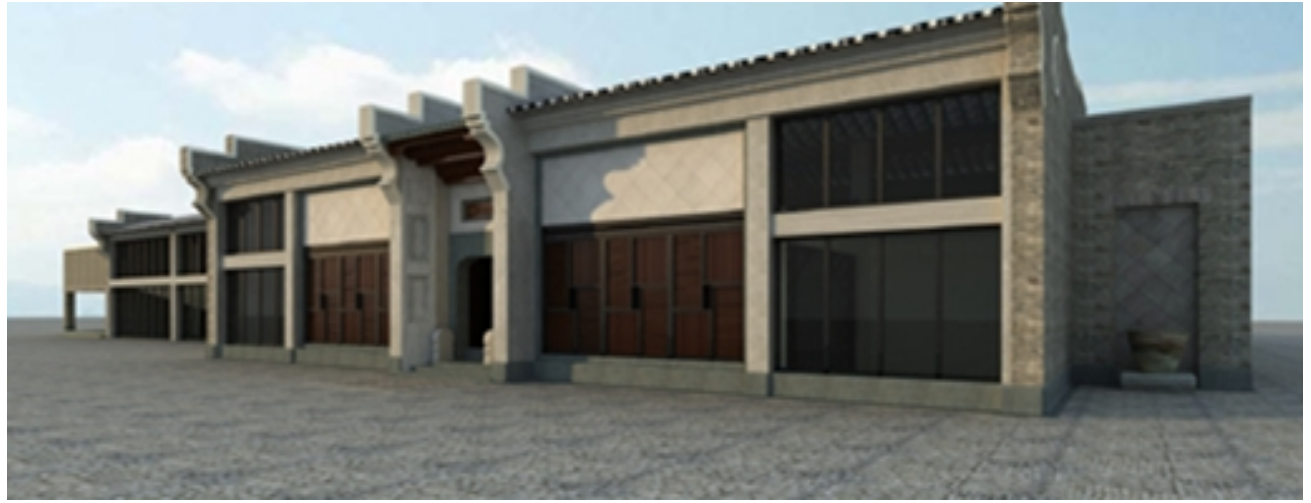

Figure 3. Dull and substantial modeling close to Yunyang residential.

Floorplanning. As an essential principle of formal beauty, the proportion has been widely valued by people since ancient times. All the modeling arts have the question of whether the dimensions 
are harmonious or not. The balance of harmony can arouse people's beauty and make the whole combination have an ideal artistic expression. The symmetrical relationship between the whole and the parts is the symmetry between the various parts of the constituent elements. Balance and harmony can meet the requirements of rationality and vision at the same time. It is the structural basis of artistic beauty.

The core issue of the plan of Yunshan Hall is to process the arrangement and comparison of a large number of sketches in different proportions based on the respect of the natural environment and the accurate and proportional representation of the various types of bodies. It is a process from abstraction to concrete, Precise start-up process. By this digital design (Fig. 4), give full play to the creativity of traditional design and the digital representation of the performance, stimulate and promote each other.
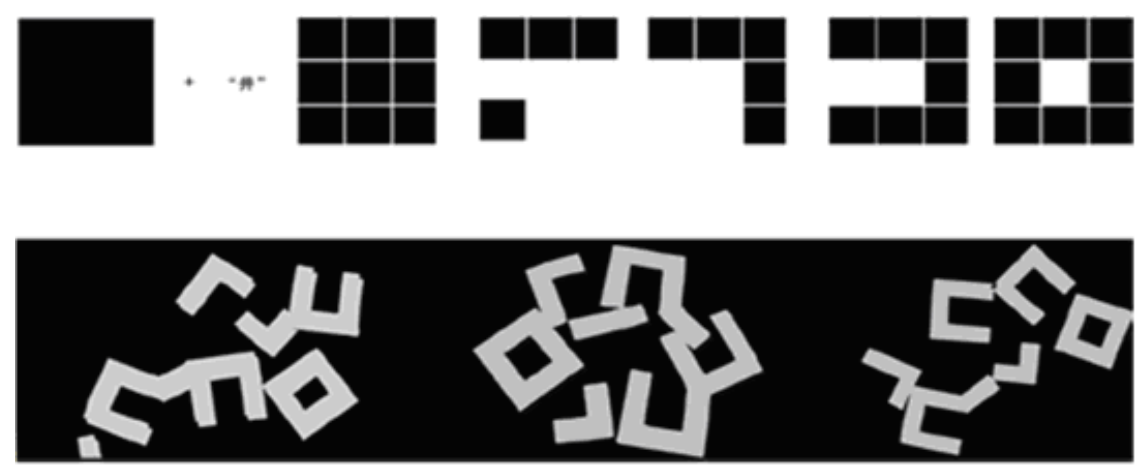

Figure 4. Two dimensional model comparison diagram.

Simulative comparison of material texture. The five aspects of material were discussed as follows.

Building materials of Yunyang private house. The private house in the northwest of Hubei Province possesses the masonry structure and style of the patio in the courtyard.The method is simple and unsophisticated, and the color is dull and neat. The bluestone, granite, and fir that are all over the mountain are all the most common materials in the south, brick and semi-cylindrical small tile are building materials that are widely used in the south.The commonly used sun-dried mud brick is made of the earth, and the manufacturing procedure is straightforward and environmental. Building materials that use local materials is not luxury: decorative openwork window, window frame, screen frame, columns, those beam structures are widely used local fir; The wall is mainly built of brick, stone or adobe bricks; The building roof is made with blue semi cylindrical small tile; Columned foundation of stoa, platform in the outside, the flag seat of the outer edge in the platform, some frames, the road built with small stone, even the stoa in the first floor were all created with local granite which is durable but also reflects the pure beauty of building materials. There are not beautiful decoration and stone lions in front of the building. Bearing stone is rectangular and little modificatory, there is carving beams of roof and gallery, which is very ugly. Ruyi which is cut on both sides of the top of the door is simple. With the top layers of eaves overhung, the blue half cylinder small tile which is covered with the roof down from segments of the floor that likes the scale. Decorative openwork window, corridor and roof pillars, as the main residential modification in the northwest of Hubei province. Fig. 5(a) is the ancient residential building materials in Tianjiaba Zhushan County of Shiyan city. They are luxurious and elegant, simple and unadorned.

The primary colors of the private house in the northwest of Hubei Province are green, soil-yellow, dark gray, gray, white and soil-red. The large blue brick and adobe wall as the keynote matches the dark gray half cylinder small tile, the beam, the column, the railing and the decorative openwork window that colors are soil-red and wood color. Gray and white of granite pillars and 
door frames, blue-gray of green brick walls and the soil-yellow of adobe wall that these colors contrast with the soil-red of interior decoration. The match between blue and soil-yellow fence sets out the flowers and trees in outside. Buildings and plants make numerous changes in the projection of the position and intensity of the sun. The entire complex is not vibrant and colorful, but the main blue keynote gives people an open and neat and elegant feel. And the color of buildings appears vividly among them. Fig. 5(b) is the private house built with different building materials and its effect on color in Huanglong Town, Shiyan city.

(a)

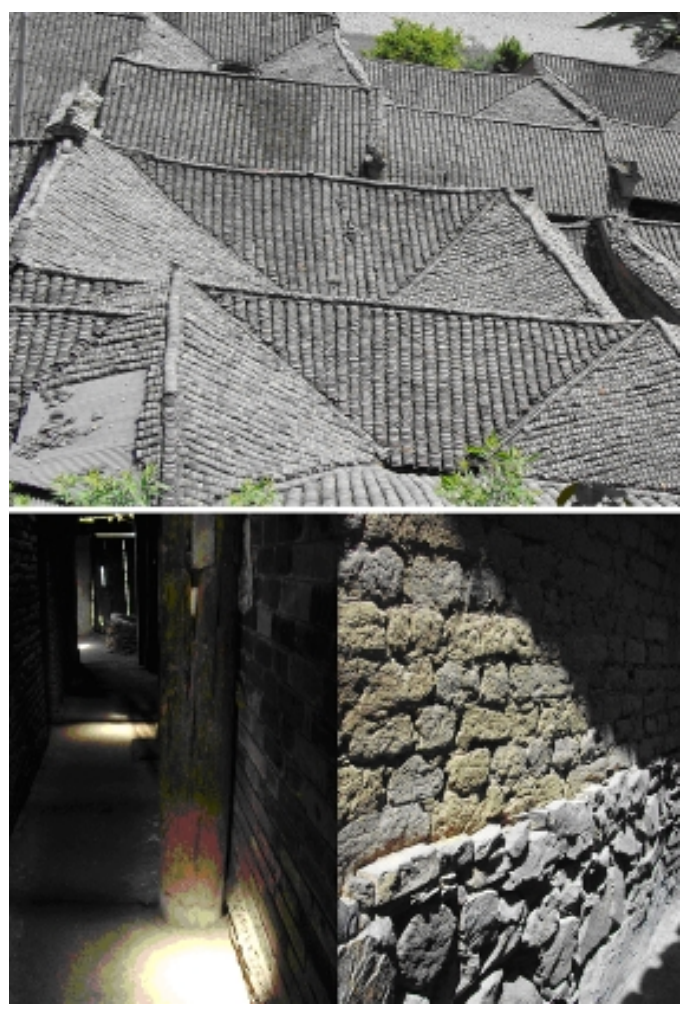

(b)
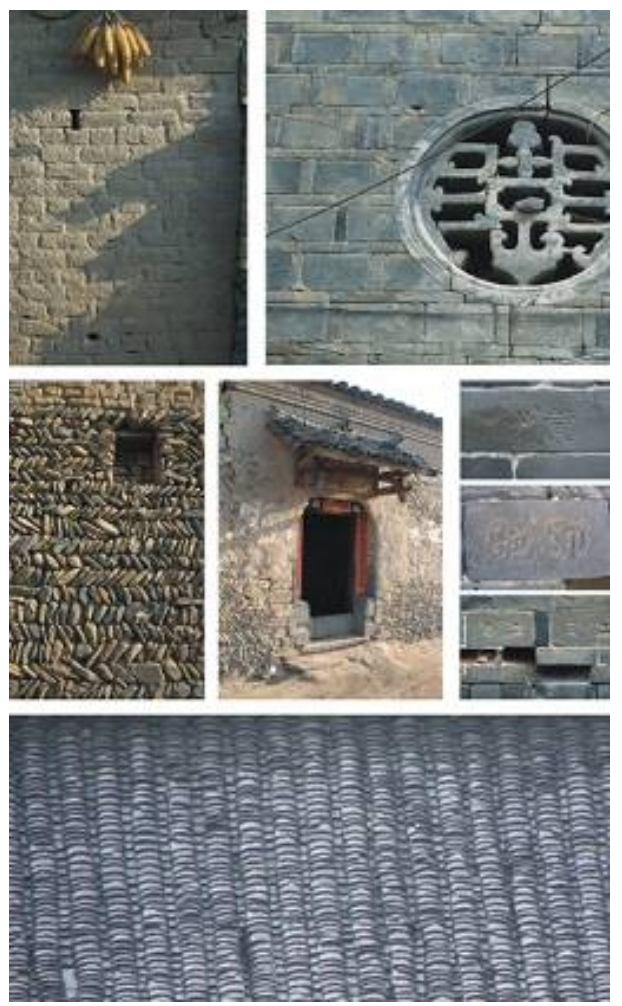

Figure 5. (a) the local residential building materials in Tianjiaba Zhushan County, (b) the part of the local materials in Huanglong town.

Use of material texture. The combination of several different materials can set up a spatial environment which is artistic and personal, and to display the quality beauty and textured beauty of the article itself. Color and pattern of the high quality material can be used for desired spatial effect, and it also can be used to cooperate with other materials to further enrich the impact of texture. Fig. 6 is the effect of the Yun Shan hall entrance under "high quality" combination.

Texture of materials. The texture is the body shape and surface texture of materials itself and the formal elements of composition that can reflect the morphological character of taste and make the feel of materials more concrete and visual. Its contents include shape, color, quality, dry and wet, thick and thin, soft and hard, glossy and lackluster, regular and irregular, transparent and translucent and other sensory factors. For example, Natural wood obtains the tactility and visual sense of wood while it is getting the texture and the color of the forest. Average experience of taste and the feel of texture in the visual mind that means it can make people experience features of texture only by visual sense without the touch of body. The surface of the plane material uses concave-convex texture color, transparency, glossiness, brightness and so on to reflect the effect of texture on the visual sense. For instance, various the decorative pattern of polished stone, wooden decorative panels, laser glass, decorative fabric, sand and other materials can visually react to 
human physiological and psychological characteristics. Owing to the difference of light, visual angle and visual distance, subtle changes in texture can be produced.

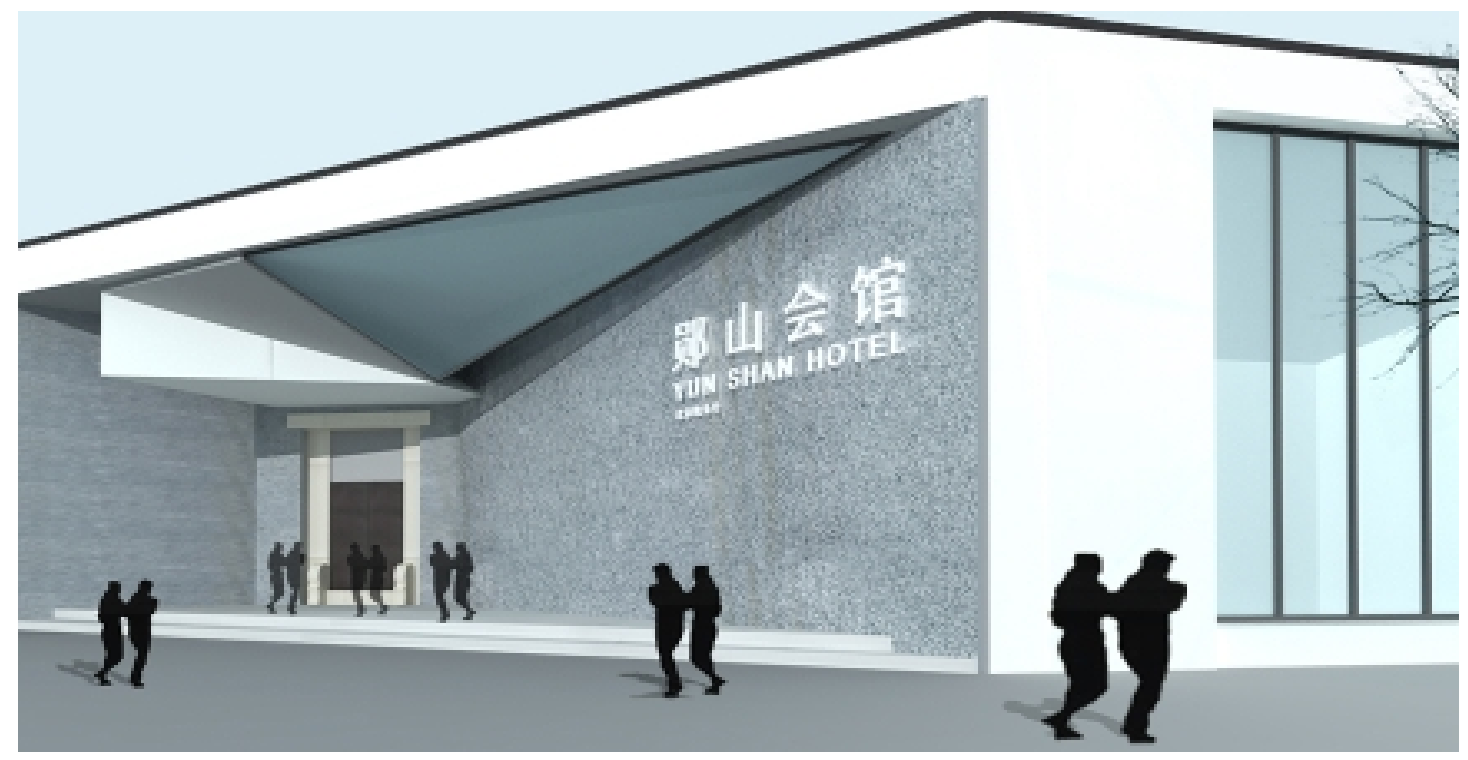

Figure 6 . The effect of treatment of high-quality materials by digital technology.

Fig. 6 is that combining all kinds of "high quality" materials and creating space environment which has modern features, strong artistic and individualization. But from the texture, it is too frosty to merge with the ideal environment of Yunyang. Fig. 7 that is also combining all kinds of "high quality" materials and creating space environment which has national features, strong artistic and individualization. Even if from the texture it is not frosty and is softer than before. And it is easier to merge with the ideal environment of Yunyang.

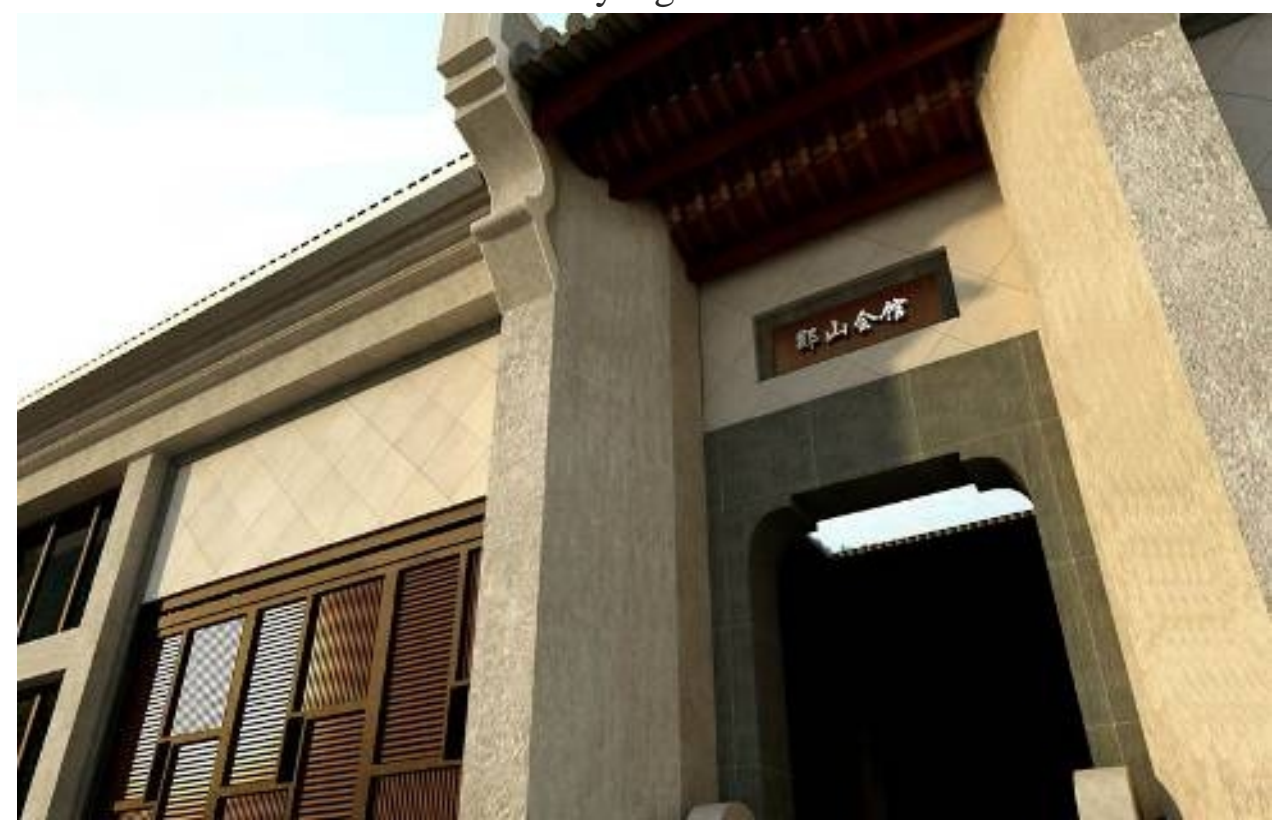

Figure 7 detail texture at the entrance of the digital technology

Quality of materials. The quality of materials has a close relation to the hue of the color of elements itself, brightness, the degree of influence by light and processing. The surface texture of materials will be influenced when it is illuminated. When transparent glass and plexiglass are penetrated directly by light, its quality will become exquisite and soft; After being explained, the polished metal surface and the glossy plastic surface will produce space reflection that will make the quality of the material become smooth, opaque, sharp contrast of bright and dark and the 
apparent thought of high light; However, surface of the sandblasting glass, sliced wooden surface, surface of concrete and exterior of the standard wall will produce diffuse reflection when they are illuminated. Then the reflected light will diffuse in the direction of 360 degrees. And the quality of materials is soft and elegant.

Fig. 8 is the combination of "high quality" materials such as sliced wooden surface, the surface of concrete and exterior of the common wall. The quality of the materials is soft, pure, generous and elegant. In the combination, the transparent glass is penetrated directly by light, and its quality is delicate and sweet which can also add the artistic and individualized space environment. Reflected natural views can better integrate into the ideal environment in Yunyang.

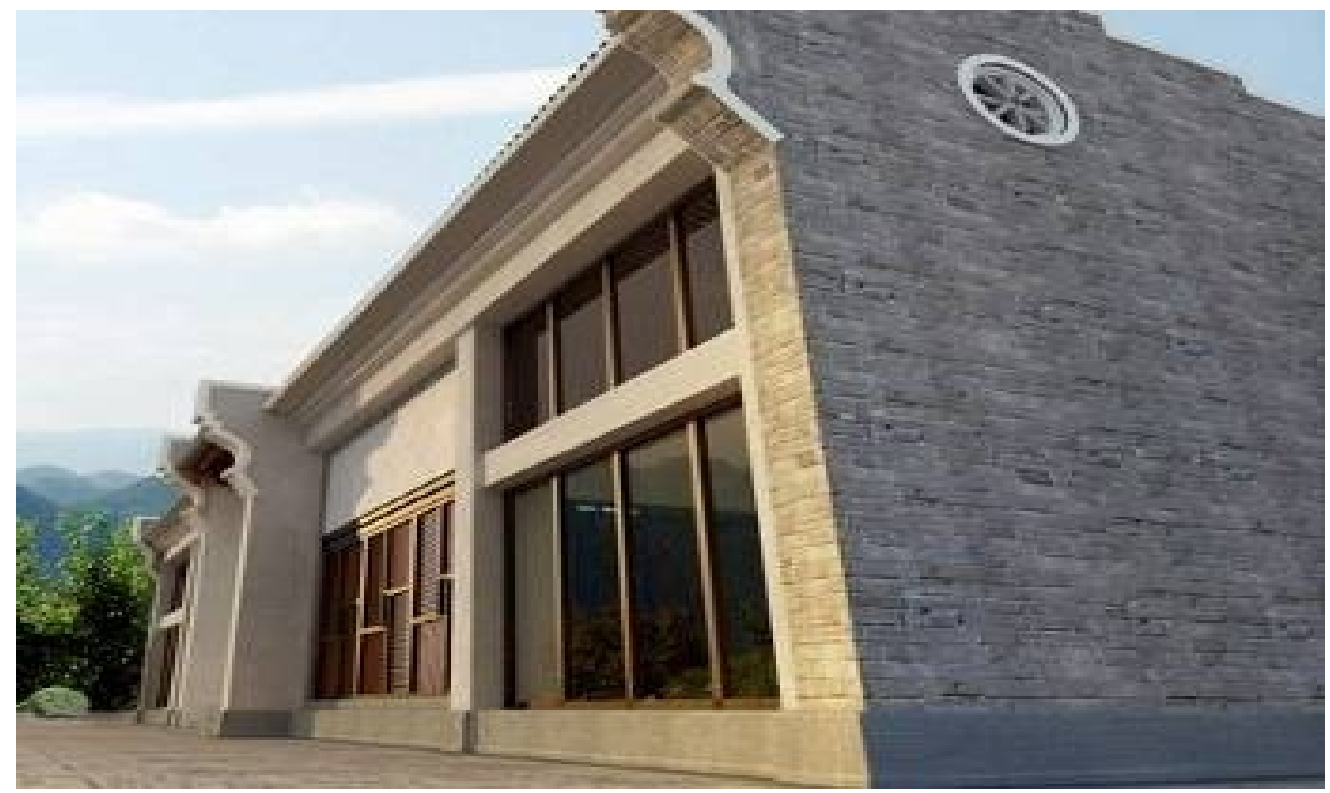

Figure 8 . The texture of out wall by using digital technology

Comparison of the texture of materials. The effect of the textured combination of building materials on the overall environmental impact cannot be ignored. We should select different elements according to the function of the space, the atmosphere and the preference of the owners. In the design, we should try to make the various material quality luxurious and straightforward, have quality and can be tasted, practical and the personality. Fig. 9 is a group of compared pictures of the courtyard, walls, doors, and windows, the ground under different light conditions in the Yun Shan clubhouse after the treatment of using the digital technology.

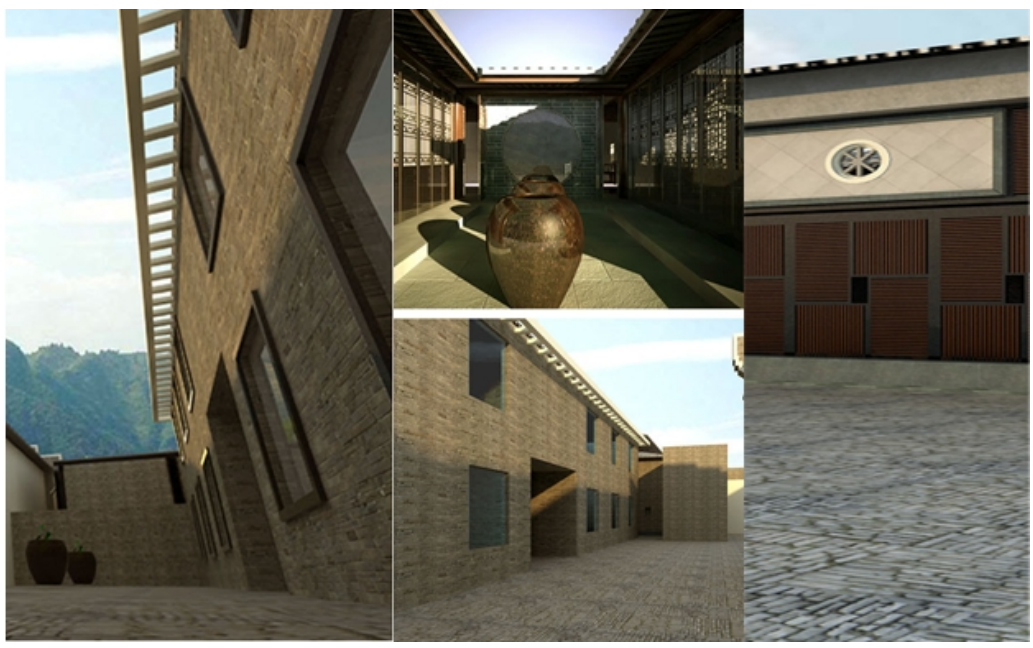

Figure 9. The comparison of texture of outside building materials. 


\section{National culture and regional culture in the Digital design}

National culture. The globalization of digital technology and the national culture of space design and diversification of cultural characteristics promote each other in the development. Because the nationality is the world, combining with the excellent traditional culture and artistic form of the country is the charm and vitality of the digital design. Therefore, digital plan must be based on broad and profound conventional culture, explored the connotation of traditional culture deeply, rooted in the fertile soil of national culture, draw on the nutrition of national culture, grasp firmly the regional characteristics of national culture, use domestic elements cleverly in the design, then works will have a lasting vitality.

Regional culture. Modern design tends to some international design ideas with ignoring regional culture. The relationship between local culture and digital design reflect the combination of traditional life and modern life which reflect both the conventional beauty and the function of advanced technology. It is the respect for regional culture and is also a perfect reflection of digital design.

With the global science and technology progressing and the information industry developing, the regional difference is becoming less, and the "earth village" is formed gradually. A lot of things lost difference and pluralism that there is a series of problems, including the regional ecological imbalance, the regional cultural disappearing, the disappearance of regional culture, and the sense of place and the sense of belonging losing. However, the different culture of all regions is one of the most important factors that can break this phenomenon. The world needs a variety of regional culture, and the diversity of regional culture leads to the diversity of design. The field of digital design which is related to the people's life closely also reflects this trend of change. Based on this idea, the design of "Yun Shan hall" is through the base of researching on the existing building of the ancient private house, and the purpose is to achieve an amalgamation of national culture and regional culture. (Fig. 10)

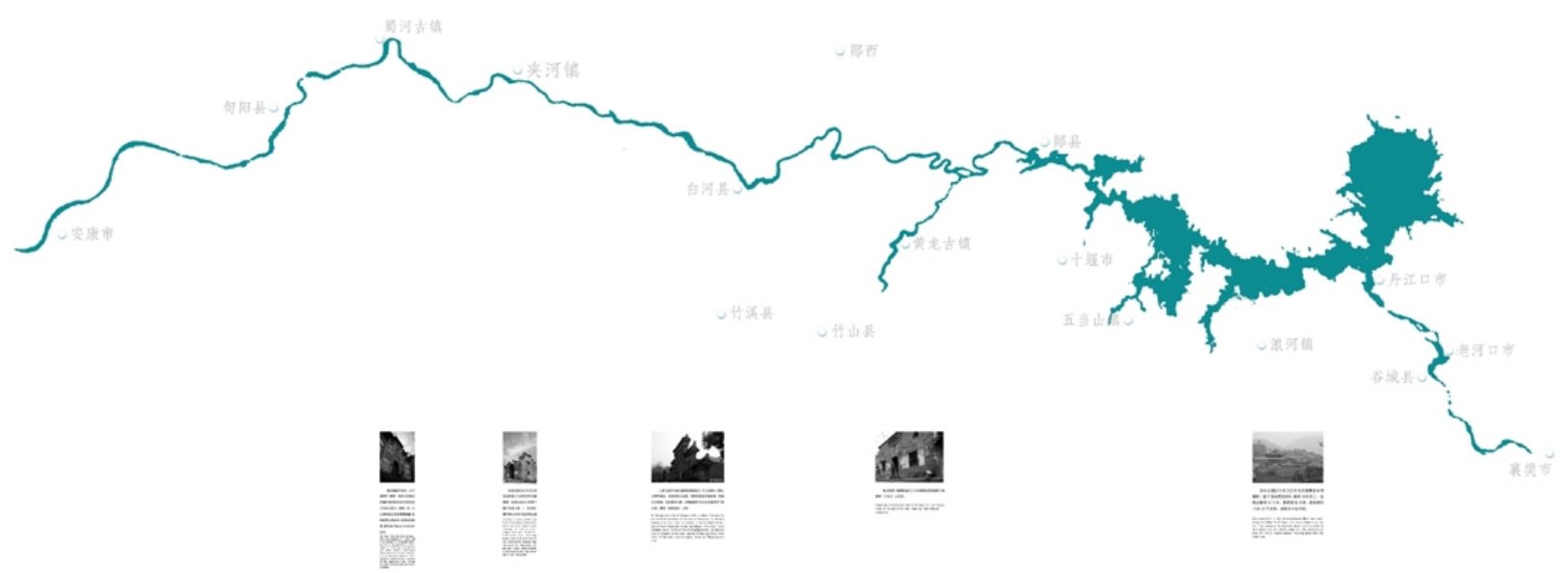

Figure 10. Ankang to Danjiangkou Han River Basin main residential distribution.

The impact of regional culture on digital design. Design of the regional refers to the absorption of social model in the design, folk and the formation of different regions of life habits, religious culture and other factors. To a certain extent, regionalism is more exclusive and concrete than nationality, and because of its geographical differences, it has strong identifiability. The more distinctive the regional culture is, the more cosmopolitan it is. It is precisely because of the characteristics of different national conditions, local lifestyle, natural shapes and other irreplaceable 
factors that make the each part has its own characteristics. The civil and meticulous construction of the southern Chinese buildings, the complex integration of the Shanghai-style structures, and the distinctive houses of ethnic minorities, as well as the various cultures formed by these regional characteristics, reflect the strong regionality and identifiability.

The traditional design techniques belong to the lower level. The values, thinking modes, philosophical thoughts, aesthetic awareness and cultural psychology reflected in the conventional design are at a higher level. One aspect is similar in appearance that is the appearance of things, but also reflects the lowest regional culture requirements and another one is alike in spirit that is our profound understanding of the local culture on the basis of absorption. Being alike in spirit, being alike in appearance and the unity of form and spirit that are three levels of "Yun Shan hall" designed concept.

\section{Conclusions}

The three aspects of modeling, modeling and real application of "Yun shan Club" design are compared in the proportion of traditional design and digital design and the same position, trying to find a win-win solution of "human brain and computer" Operating mode. In the process of work found that if designers' one-sided pursuit of digital performance technology, often only pay attention to the effect of paper and neglect the latter part of the actual use of "beauty" and "realistic" instead of the design. "Yunshan Hall" design efforts to optimize the digital technology process, so that the flow of design thinking and technical stream of milk smooth integration, in the performance of modern technology at the same time emphasize people's awareness of design, attention to human nature, especially the design of the combination of national culture And the connotation of the regional culture, so as to optimize the digital design technology platform so that the digital model can achieve more significant development in the field of space design.

\section{Acknowledgements}

This work was financially supported by the Research Project of Hubei Provincial Department of Education (B2015365) and the National Natural Science Foundation of China (NSFC 41701483).

\section{References}

[1] Ren, Z. The application of digital technology in space design, Wuhan University. (2006)

[2] Yunxian local chronicles Compilation Committee sign. Yunxian records. (2008)

[3] Ding, J.Q. Chinese residential culture. Shanghai, China: Tongji University Press, P. 179. (1998)

[4] Ding, Y.M. Engineering graphics development for interdisciplinary. Journal of Wuhan University (Engineering Edition).34(6):75-78. (2001)

[5] Ren, J. Chinese traditional courtyards from the Cultural Perspective. Tianjing, China: Tianjin University Press, P. 22. (2005)

[6] Jin, X.Z. Chinese Garden Aesthetics. Nanjing, China: Jiangsu Literature and Art Publishing House, P. 132. (1990) 